\title{
Der bewegte Augenblick
}

\section{Erhard Taverna}

Dr. med., Mitglied der Redaktion

Nu descendant un escalier $n^{\circ} 2$ nannte Marcel Duchamp (1887-1968) sein gemaltes Bild. Heute ein Schlüsselwerk der klassischen Moderne, provozierte das Werk 1912 in Paris einen Skandal. Die Welt als Abbild ineinandergeschobener Momentaufnahmen, Zersplitterung statt Stillstand, eine unbekannte Ästhetik der Unruhe.

$\mathrm{Zu}$ dieser neuen Sichtweise hat Etienne-Jules Marey (1830-1904) viel beigetragen. Mediziner, Physiologe, Erfinder zahlreicher elektrokardiographischer Geräte und Pionier der wissenschaftlichen Fotografie. Viele Wege führen zu ihm. Zum Beispiel über den Eisernen Steg vom Römer zum Schaumainkai. Dort am Frankfurter Main wartet eine ganze Zeile Museen auf ihre Besucher, Architektur, Kommunikation, Skulpturen und das deutsche Filmmuseum. Wallace \& Gromit, Shaun \& Co. sind in Vorbereitung (Ausstellungseröffnung am 12. Juni). Das Thema «Filmisches Sehen» befasst sich im ersten Teil der Dauerausstellung mit der Erfindung des Films bis 1895. Eine Vitrine erinnert an Etienne-Jules Marey, in einer Reihe mit den Brüdern Auguste und Louis Lumière und Eadweard Muybridge, einem weiteren Pionier der Chronofotografie. Die neue Technik machte Bewegungsabläufe sichtbar, die das Auge nicht erkennt. Der Engländer studierte Rennpferde, der Franzose, Professor am Collège de France, interessierte sich vor allem für Sportathleten. Dazu publizierte der Arbeitsphysiologe viele populäre Studien, zum Beispiel Du mouvement dans les fonctions de la vie oder Etudes pratiques sur la marche de l'homme. Sein Assistent entwickelte einen der ersten Kraftsporttrainer für das gut betuchte Pariser Bürgertum. Das Wort «Training» eroberte die muskelbe-

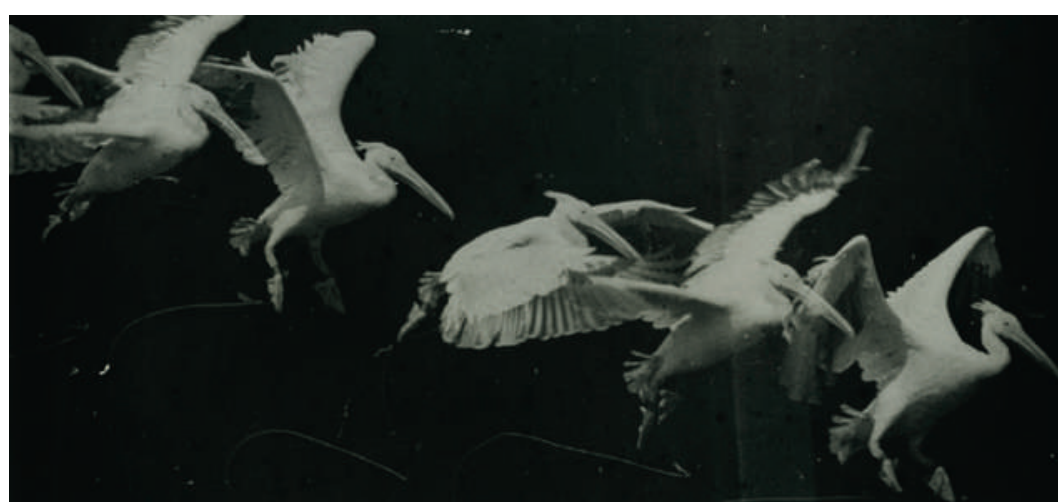

Marey, Chronofotografie eines Pelikanflugs, um 1882. (Foto: https://de.wikipedia.org/ wiki/\%C3\%89tienne-Jules_Marey)

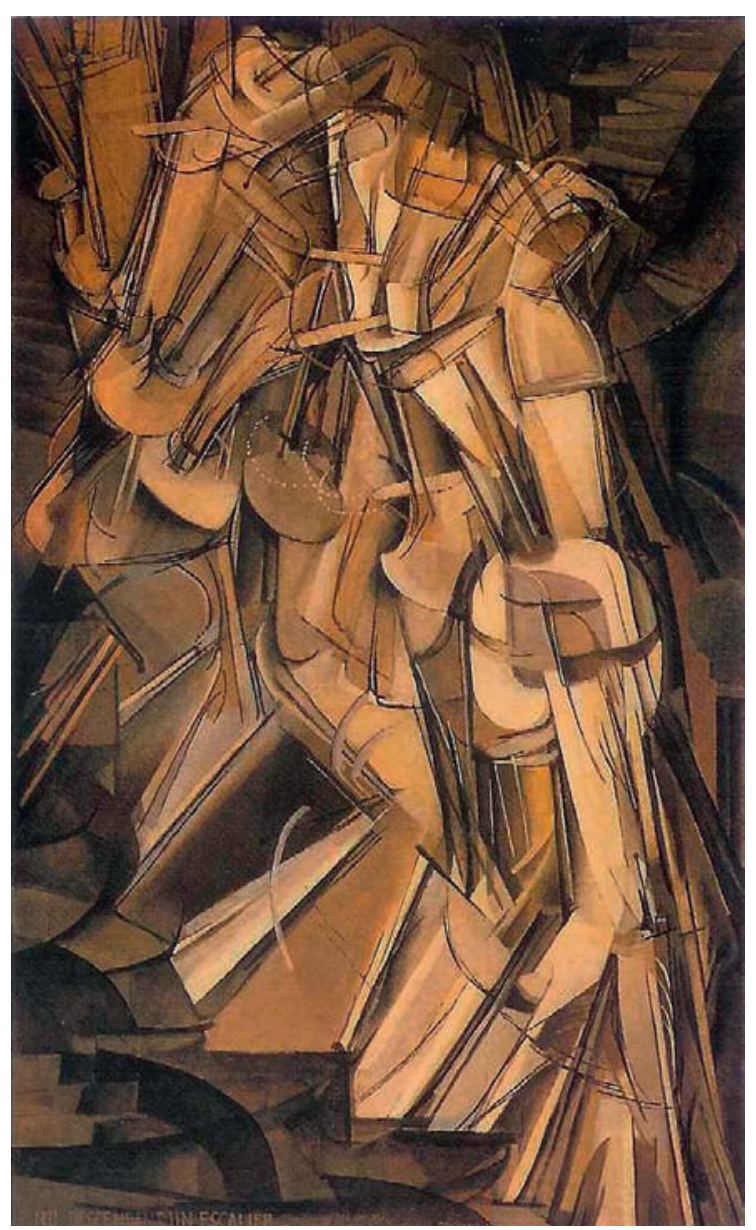

Duchamp, Nude Descending a Staircase No. 2, 1912 (Foto: https://en.wikipedia.org/wiki/Marcel_Duchamp)

wusste Männer- und Damenwelt. Diät und Bewegung sollten Blutkreislauf und Stoffwechsel fördern. Mareys Serienbilder von bewegten Körpern propagierten die Hygieneansichten der Zeit. 1900 fanden im Rahmen der Weltausstellung in Paris Olympische Sommerspiele statt. Die Leibesübungen an öffentlichen Schulen wurden den neuen Erkenntnissen angepasst, Marey wurde im gleichen Jahr zum Ritter der Ehrenlegion ernannt. In der gleichen Vitrine liegt seine chronofotografische Flinte. Eine auf einem gewehrähnlichen Stativ montierte, zylindrische Kammer, in der eine lichtempfindliche Glasplatte rotierte. Marey fotografierte damit Vögel und gehende Menschen. Ein Vorläufer der Hochgeschwindigkeitsfotografie, die heute mit Stroboskopblitzen weit kürzere Belichtungszeiten ermöglicht. 
Der Einfluss des Erfinders reichte weit über seinen Fachkreis hinaus, denn die industrielle Revolution veränderte auch die Wahrnehmung des Alltags. Die Eisenbahn liess Raum und Zeit zusammenschrumpfen, die Glas-Stahl-Architektur der Bahnhöfe und Gewächshäuser brachte koloniales Leben in die imperialen Grossstädte. Die Fotografie als Massenmedium fasziniert auch Maler und Schriftsteller. Alles geriet in Bewegung, der festgefügte Raum erwies sich als Illusion. Die dynamischen Darstellungen der forschenden Physiologen wurden vor allem vom Kreis der Futuristen begeistert aufgenommen, die Maschinenkraft und Tempo verherrlichten. Mareys Gehende Person von 1890/91 könnte Marcel Duchamp zu seinem Werk inspiriert haben. Physiologie und Hygiene begründeten eine neue Körperkultur der Muskelkraft. Die Bildmon- tagen von Läufern, Schwimmern und Radrennfahrern verliehen der Zeitdimension eine weitere Bedeutung. Die sichtbar gemachte Wirklichkeit ist nun ununterbrochene Aktion und Verwandlung. Die nachfolgende Künstlergeneration erfindet eine neue Sprache für die sozialen Auswirkungen der aktuellen Erfindungen, die das Weltverständnis Ende des 19. Jahrhunderts grundlegend und folgenreich bis in unsere Zeit verändert haben.

\section{Dauerausstellung Sehen \& Erleben}

Deutsches Filmmuseum

Schaumainkai 41

60596 Frankfurt am Main

www.deutsches-filmmuseum.de 